\title{
Orotraqueal intubation training in the coronavirus pandemic: application of the rapid cycle deliberate practice
}

\author{
Treinamento de intubação orotraqueal na pandemia por coronavírus: aplicação da Prática Deliberada em \\ Ciclos Rápidos
}

\author{
Rodrigo Pereira Diaz André1 (1) |diaz.rodrigo@globo.com \\ Hudson Carmo de Oliveira' (D) hudoliver@hotmail.com \\ Glauber Gouvêa' 1 (D) glauber.gouvea@gmail.com \\ Fátima Carneiro Fernandes' (D) fatimacfernandes@gmail.com \\ Ingrid Régia Lopes Jerônimo' (1) ingridregia@hucff.ufrj.br \\ Juliana Faria Campos ${ }^{1}$ (D) $\mid$ jujufariacampos@yahoo.com.br
}

\begin{abstract}
Introduction: the coronavirus pandemic disclosed the need for safe orotracheal intubation not only for the patient, but also for the professionals involved in the procedure. Therefore, training and technique reviews became necessary.

Objective: this article aims to propose the application of the Rapid Cycle Deliberate Practice (RCDP) strategy for the training of anesthesiologists in orotracheal intubation in people with confirmed or suspected COVID-19 and to present a guide for the application of this strategy in this situation.

Method: This is a methodological study presenting the theoretical and operational aspects for the Rapid Cycle Deliberate Practice application and a guide constructed from the search for evidence published in journals and official recommendations published by the institutions linked to the Brazilian and international health area.

Results: the main theoretical aspects reported are related to the three principles on which Rapid Cycle Deliberate Practice is based: maximizing time in deliberate practice, targeted feedback, and explicit psychological security. As for the operational aspects, it is highlighted that the training must be carried out with a maximum of six people. An error must be interrupted, prescriptive feedback must be given, and the task must be performed again until the participant reaches mastery. As for the procedure technical specificity, a guide to the application of the rapid cycle deliberate practice is presented with the sequence for the adequate airway management of hypoxemic patients with suspected or confirmed COVID-19 infection.
\end{abstract}

Conclusion: it is concluded that the assessed instructional strategy showed to be promising for the training with mastery learning in all professionals who will perform the procedure of orotracheal intubation while facing the severe forms of COVID-19, minimizing the risk of contamination.

Keywords: Coronavirus Infections; Intratracheal Intubation; Pandemics; Simulation Training.

\section{RESUMO}

Introdução: A pandemia por coronavírus revelou a necessidade de intubação orotraqueal de forma segura não apenas para o paciente, mas igualmente para os profissionais envolvidos no procedimento. Para isso, treinamentos e revisões de técnicas se tornam necessários. Objetivo: Este artigo tem por objetivos propor a aplicação da estratégia de Prática Deliberada em Ciclos Rápidos (PDCR) para treinamento de anestesiologistas na intubação orotraqueal em pessoas confirmadas ou suspeitas com Covid-19 e apresentar um guia para aplicação dessa estratégia nessa conjuntura.

Método: Trata-se de estudo metodológico que apresenta aspectos teóricos e operacionais para a aplicação da PDCR e um guia de aplicação construído a partir da busca de evidências publicadas em periódicos e recomendações oficiais divulgadas pelos órgãos vinculados à área da saúde brasileira e internacional.

Resultado: Os principais aspectos teóricos relatados são concernentes aos três princípios que baseiam a PDCR: maximização do tempo em prática deliberada, feedback direcionado e segurança psicológica explícita. Quanto aos aspectos operacionais, destaca-se que o treinamento deve ser realizado com o máximo de seis pessoas. Deve-se interromper o erro, fornecer um feedback prescritivo e pedir que a tarefa seja realizada novamente até atingir a maestria. Quanto às especificidades técnicas do procedimento, apresenta-se um guia de aplicação da PDCR com a sequência para o adequado manuseio de vias aéreas de pacientes hipoxêmicos suspeitos e positivos para Covid-19.

Conclusão: A estratégia instrucional estudada mostra ser propícia a treinar com maestria os profissionais que realizarão o procedimento de intubação orotraqueal no enfrentamento das formas graves da Covid-19, visando minimizar o risco de contaminação.

Palavras-chave: Infecção por Coronavírus; Intubação Intratraqueal; Pandemia; Treinamento por Simulação.

${ }^{1}$ Universidade Federal do Rio de Janeiro, Rio de Janeiro, Rio de Janeiro, Brazil.

Chief Editor: Rosiane Viana Zuza Diniz.

Associate Editor: Kristopherson Lustosa Augusto.

Received on 01/21/21; Accepted on 04/29/21.

Evauated by double blind review process. 


\section{INTRODUCTION}

The World Health Organization, on March 11, 2020, declared that the disease caused by the new coronavirus, called COVID-19, has become a pandemic. In May 2020, the statistics showed almost 4.5 million confirmed cases and 302,059 deaths in more than 210 countries $^{1}$. Data indicate that $14 \%$ to $20 \%$ of cases infected with the severe acute respiratory syndromerelated coronavirus 2 virus (SARS-CoV-2) may progress to severe acute respiratory syndrome (SARS) ${ }^{2,3}$. That said, the need for orotracheal intubation was identified in $2.3 \%$ of 1,099 confirmed COVID-19 patients, in a cohort of 552 hospitals in 30 Chinese provinces ${ }^{2}$, in $47 \%$ of 36 patients admitted to the ICU at Zhongnan ${ }^{3}$ hospital, and in $42 \%$ of 52 patients admitted to the Intensive Care Unit at Jin Yin Tan hospital, both in Wuhan ${ }^{4}$.

Given the highly contagious nature of SARS-CoV-2 and its droplet transmission, as well as it potential aerosolization in some procedures ${ }^{5}$, airway intubation carries a high risk of contamination for professionals involved with this procedure. A Chinese Anesthesiology Society guideline reports the contamination of many anesthesiologists during orotracheal intubation procedures in individuals with confirmed COVID-19 infection, although scarce statistical data are known on the current pandemic ${ }^{6}$. However, it is known that during the SARS outbreak in 2002, $21 \%$ of infected individuals globally were health professionals ${ }^{7}$. Data from a Canadian study reveal that out of 251 confirmed SARS cases, $43 \%$ of them occurred in healthcare professionals, which leads to a reflection on the potential for contamination of these agents despite the seemingly adequate attire?

The handling of these patients' airways in the context of a pandemic implies distinct challenges that generate additional risks for both patients and health professionals. In relation to patients, there is a risk of their having a difficult airway and consequent complicated intubation as, in the presence of respiratory failure, they may have already exhausted the ventilatory compensatory mechanisms. Among the involved health professionals, the increased risk of crossinfection represents a technical and psychological challenge in performing the task ${ }^{8}$.

Studies show that the failure to update professionals and the absence of repeated practice result, over time, in technique deviations or stagnant skills ${ }^{9}$. In addition, retention intervals, which are prolonged periods without practicing a certain skill, resulting in performance decline ${ }^{9}$. Thus, conducting the training with all professionals involved in assisting patients with COVID-19 is extremely important ${ }^{10}$. Training, including putting on and taking off PPE and process simulation tests for critical and non-critical cases, including airway management, should be conducted to identify system gaps and problems. Health services must ensure that adequate resources (staff time and equipment) are provided for training and for the simulation of airway handling scenarios in preparation for COVID-19 ${ }^{11}$.

It is believed that the professional's adequate preparation to perform the procedure can minimize the chances of contamination and improve performance. A study carried out in two hospitals in Wuhan, China, analyzed a series of 202 patients with coronavirus disease (COVID-19) submitted to tracheal intubation by anesthesiologists. The study reports zero rate of virus transmission among professionals who performed intubations, due to investment in educational training practices for adequately putting on and taking off PPE and monitoring of the procedure. It also emphasizes that there was no evidence of cross-infection in these professionals, even after 14 days of the procedure, suggests individualized training and considers the possibility of simulation before performing intubation in patients with COVID-198.

From this perspective, an innovative simulation strategy whose objective is to improve the participants' performance can be useful in this scenario. Called the 'Rapid Cycle Deliberate Practice' (RCDP), the strategy promotes the repetition of tasks until mastery of the skill has been attained and, for this, the participants are accompanied by an instructor responsible for providing evidence-based feedbacks ${ }^{12}$. Therefore, it is understood that the RCDP is an instructional simulation strategy centered on the learner, which can be applied to the qualification and training with mastery of anesthesiologists for the orotracheal intubation procedure, as well as in the putting on and taking off of PPE, aiming to meet the current pandemic demands ${ }^{13}$. Therefore, this article aims to propose the application of the Rapid Cycle Deliberate Practice (RCDP) strategy for the training of anesthesiologists in orotracheal intubation in individuals with confirmed or suspected COVID-19 infection and present a guide for the application of this strategy in this context.

\section{MATERIALS AND METHODS}

This is a methodological study that presents an instructional simulation strategy to be used as a training method for anesthesiologists performing orotracheal intubation in individuals with confirmed or suspected COVID-19 infection. The study was structured in two stages. In the first stage, an exploratory search for evidence on the main updates for orotracheal intubation in the context of the pandemic was carried out. The main official guidelines and recommendations published by the institutions linked to the Brazilian and international health area were considered: World Health Organization, Ministry of Health of Brazil, National Health Surveillance Agency (Anvisa, Agência Nacional de Vigilância Sanitária) and anesthesiology societies. Also included 
were reports of experiences and specialists' consensuses on the subject published in journals between January and December 2020. This search was carried out on Academic Google and on the Elsevier search platform, of which access was openly made available during the COVID-19 pandemic.

In the second stage, the training method was developed based on the union of the theoretical and operational aspects of the instructional strategy in question, entitled Rapid Cycle Deliberate Practice ${ }^{12}$, with the main evidence and guidelines found on the topic of orotracheal intubation. All theoreticaloperational aspects were based on the original study of Rapid Cycle Deliberate Practice ${ }^{12}$ and on complementary studies on this strategy ${ }^{13,14}$. It is noteworthy that the basis for these studies is based on research about the acquisition of skills, expertise and deliberate practice by Ericsson et al. ${ }^{15}$. In accordance with the Rapid Cycle Deliberate Practice, a guide for the application of this strategy in the studied context was also created.

This study was developed as a result of the partnership between professionals who study the field of clinical simulation, including RCDP, and anesthesiologists who work in care and / or teaching at a reference teaching hospital in Brazil. It is noteworthy that the technical contents of orotracheal intubation were evaluated and reviewed by these authors.

\section{RESULTS}

\section{Theoretical Aspects of the Rapid Cycle Deliberate Practice}

To understand the Rapid Cycle Deliberate Practice, it is necessary to approach the concept of Deliberate Practice, coined by Ericsson et al., in studies on the acquisition of skills and expertise ${ }^{15}$. These studies explain that people can improve their performance through common practice or with the help of third parties, such as teachers or supervisors and, with the acquired experience, they can act more rapidly, achieving automatization. However, when they reach this stage, they lose conscious control over the task performance, which prevents them from making improvements. In order to allow a performance improvement beyond the automatization line, they must then perform the deliberate practice. This term is defined as a sequence of specific activities whose objective is to improve the individuals' performance by submitting them to the following factors: a) a task with a defined objective; b) motivation to improve; c) feedbacks; and d) vast opportunity for repetition and gradual refinement of the performance ${ }^{15}$.

The Rapid Cycle Deliberate Practice appropriates the concept of Deliberate Practice but uses clinical simulation as the technical basis to apply it. Created in 2014 by Hunt et al. in a pediatric cardiopulmonary resuscitation scenario, the RCDP explores a clinical case encouraging the individual to practice tasks until mastery is attained. For this purpose, it includes a quick transition between these tasks and the targeted feedback provided by an instructor. It can be observed, then, that the RCDP maintains the factors inherent to the concept of Deliberate Practice, but organizes its own conceptual aspects, called principles ${ }^{12}$.

The first principle of RCDP is the maximization of time in the deliberate practice, which means granting several opportunities for the repetition of tasks. The purpose is to reach the level of automatization together with mastery, creating muscle memory to do the right thing. Thus, it is necessary to receive information from an instructor to shape the skill. This received information is called 'feedback', which are provided when a performance error is found, classifying them as targeted and immediate ${ }^{12,13}$.

The second principle is exactly the provision of evidencebased feedback. For it to be possible, instructors must have mastery of the topic covered in the simulation. They must also have confidence in the application of the RCDP strategy. As its name suggests, evidence-based feedback must contain the most current scientific information found in the literature or take into account the experts' consensus. In order to provide it, the instructor will make brief and assertive interruptions aiming to clearly state the evidence. It is not appropriate to ask reflective questions or carry out reflective debates during RCDP training. The idea is for the instructor to offer the evidence in a prescriptive way, while the participant receives it and goes back to carrying out the task, repairing the action that generated the feedback. In case of persistence of the error, new feedback will be provided, creating a rapid cycle between task, interruption and feedback, called feedback-repetition cycle or rapid cycle ${ }^{12-14}$.

The third principle is concerned with the quality of receiving feedbacks. It was thought of due to the possible defensive behavior the participant can adopt when successively corrected. To avoid this stance and allow corrections to be favorably accepted, the third and last principle is called explicit psychological security. The training does not start without clarifying that continuous feedbacks are essential to achieve a masterful performance. It is necessary to establish an agreement between instructor and participants to provide a comfortable training environment, ensuring that participants are aware that they will be interrupted and corrected and will be seen in the same way a coach sees a high-performance athlete. This characterizes the dynamics as a coaching style ${ }^{12,13}$.

\section{Operational Aspects of the Rapid Cycle Deliberate Practice in Orotracheal Intubation}

In terms of operationalization for the application of the RCDP, the number of participants recommended in other studies is a minimum of two, and a maximum of five to six ${ }^{12,13}$. 
However, this number has been shown to be empirically variable. For Orotracheal Intubation in the context of a Covid-19 pandemic, aiming to avoid contamination by the new coronavirus, it is recommended that the procedure be performed by two professionals: an intubator and an assistant ${ }^{16}$. Thus, it is suggested that the training be carried out in pairs, with a maximum of six participants. While two are performing the tasks and receiving feedbacks, the others will be positioned so that they can observe and hear the feedbacks given to the colleagues in training, until there is a rotation ${ }^{13}$. The dynamics of the exchange of participants is linked to the steps of the application guide.

Respecting the principles of the RCDP, the initial act of training should focus on ensuring psychological security ${ }^{12}$; for that, the trainer explains the entire dynamics of the simulation, highlighting the benefits of a skilled performance; in this case, avoiding self-contamination, ensuring patient safety and providing quality invasive mechanical ventilation. It should be stressed that, by taking on the role of instructor, they are responsible for helping participants to perform tasks flawlessly, aiming to create muscle memory without errors ${ }^{12}$, resulting in an improved performance. This entire explanation must be provided in a charismatic and welcoming manner. It is at this moment that the agreement pertaining to the coaching style is declared ${ }^{12,13}$.

The second act of the trainer is to present all the equipment available in the simulation and decide / ask who will be the first pair ${ }^{13}$. Next, the clinical case is described and the practice begins, with the chosen pair performing the first activity. If there is an error, the trainer interrupts them and provides targeted, prescriptive and immediate feedback ${ }^{12-14}$. It is worth ratifying that the feedback must explicitly contain the scientific evidence ${ }^{13}$. To illustrate the correct way to provide feedback on the RCDP in the context of orotracheal intubation, the following example was considered: the participant did not install the High Efficiency Particulate Air (HEPA) filter between the mask and the Continuous Positive Airway Pressure (CPAP) valve. The trainer must say: "It is necessary to install the HEPA filter between the mask and the CPAP valve, according to Technical Note n. 4 of 2020 from ANVISA to filter the virus and decrease the chance of contamination"16. If the participant makes the same mistake again, the interruption should be as follows: "Let's stop, go back 10 seconds and try again"12,13.

The pair that started the training needs to complete the first stage of the guide, flawlessly, so that the first rotation can take place. After the exchange, the second pair must also start to carry out the tasks of the first stage until they can complete it without errors. The same occurs with the last pair. When everyone completes the first stage, the coach will start the second one and so forth; however, regardless of the stage being trained, after the rotation, one should always start with the first stage ${ }^{13}$. It is also recommended that the pair switch between each other, allowing both to perform the roles of intubator and assistant.

\section{Guide to the Application of the Rapid Cycle Deliberate Practice}

The guide consists of specific tasks divided into six stages (Chart 1). The first covers the attire, while the second concerns the initial procedures and the patient preparation. The third stage covers pre-oxygenation, while the fourth comprises the rapid sequence induction tasks. The fifth stage refers to orotracheal intubation and the last covers the unattire. Each task in the guide was developed in a way that considers it a critical point and, therefore, should not be ignored. The error of a critical point would result in potential contamination of the professional and / or the patient, as well as negatively interfere in the provided care.

Chart 1. Guide for RCDP in airway management of hypoxemic patients with suspected or confirmed COVID-19 infection.

\section{Phase 1 - Surgical attire}

Put on surgical attire with PPE (see RCDP article for attire and unattire ${ }^{13}$ ).

Put on 02 pairs of gloves when approaching the bed.

Checking of PPE by two different professionals (Intubator and Assistant).

\section{Phase 2 - Initial procedures and patient preparation}

Guarantee a maximum of 2 anesthetists by the Patient's Bed, another anesthetist is wearing the attire outside to provide any assistance.

Check medication kit with induction drugs and aspirated drugs:

- $\quad$ Propofol 160mg + Lidocaine: $80 \mathrm{mg}$ (aspirated together in a $20 \mathrm{~mL}$ syringe)

- Fentanyl $150 \mathrm{mcg}$

- Succinylcholine $100 \mathrm{mg}$

- $\quad$ Ephedrine (10mg / mL solution)

- Atropine (250mcg / mL solution)

- Phenylephrine (40mcg / mL solution)

- Epinephrine $(5 \mathrm{mcg} / \mathrm{mL}$ solution)

- Norepinephrine (16mcg / mL solution) 
Chart 1. (Continuation) Guide for RCDP in airway management of hypoxemic patients with suspected or confirmed COVID-19 infection.

\section{Phase 2 - Initial procedures and patient preparation}

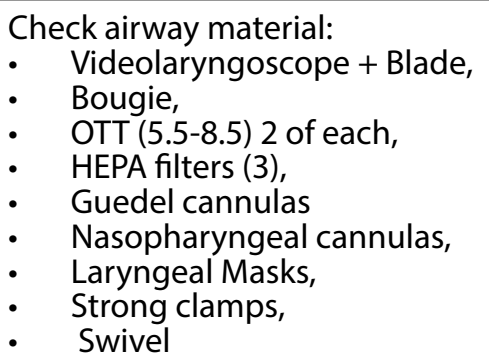

Leave OTT ready with Swivel and Bougie. (Fig 1) Use the red filter cover, occluding the main Swivel outlet.

Install HEPA filter between the Mask and the CPAP Valve (connected to the Mapleson C system) (Fig. 2), or between the mask, bag and valve (if there is no CPAP Valve).

Check with the local team if the mechanical ventilator has been tested by personnel in the sector (Intubator).

Check if HEPA filter is installed between the expiratory branch of the mechanical ventilation circuit (Assistant), confirm it out loud.

Check all extensions of the ventilator circuit (Assistant) and reinforce them in order to avoid disconnections during the procedure, confirm it out loud.

Check Mapleson C System equipment connections and reinforce them in order to avoid disconnections during the procedure (Intubator), confirm it out loud.

Check if the aspiration system is working (Intubator), confirm it out loud.

Check if the $\mathrm{O}_{2}$ flow system is working in a flow meter at the Wall gas outlet or in an $\mathrm{O}_{2}$ cylinder (Intubator), confirm it out loud.

Check for the presence of a crash cart close to the bed (Intubator), confirm it out loud.

Check for presence and ask the local team if the defibrillator has been tested (Intubator).

Check the presence of 2 waste bins, one on each side of the bed (Assistant), confirm it out loud.

Check for presence and permeability of venous access (Assistant) with $5 \mathrm{~mL}$ of $0.9 \%$ SS, confirm it out loud.

Connect TriWays with coupled induction medications (Assistant) (Fig. 3), confirm it out loud.

Check if the patient is correctly monitored (Assistant), confirm it out loud.

\section{Phase 3-Pre-oxygenation}

Position the patient to maximize safe apnea time (Intubator).

Seal the face mask tightly in the V / E position (Intubator).

Perform pre-oxygenation for 3-5 minutes with: $100 \% \mathrm{O}_{2}$, always with HEPA filter, $2 \mathrm{~L} / \mathrm{min} \mathrm{O}_{2}$ flow, maintaining CPAP valve at 5 $\mathrm{cm} \mathrm{H}_{2} \mathrm{O}$ (Intubator).

\section{Phase 4 - Rapid sequence induction}

Perform anesthesia and deep muscle relaxation (Intubator requests and Assistant administrates it):

- Fentanyl $150 \mathrm{mcg}$ in the third minute of pre-oxygenation

- Lidocaine: $80 \mathrm{mg}$ + Propofol $150 \mathrm{mg} 01$ minute after the fentanyl (Lidocaine aspirated together with Propofol)

- Succinylcholine: $100 \mathrm{mg}$ (or Rocuronium: $100 \mathrm{mg}$ as soon as the patient is unconscious

Ensuring complete neuromuscular block before attempting tracheal intubation.

Do not perform periglottic anesthesia.

If necessary, request technical maneuvers such as Backward Upward Right Pressure (BURP) to the assistant (Intubator).

If manual ventilation is required:

- Use low tidal volumes $(200-250 \mathrm{~mL})$ under low pressure $\left(15-20 \mathrm{cmH}_{2} \mathrm{O}\right)$,

- Preferable four-hand ventilation technique to prevent leakage (through the mask, around the nose and chin)

- Use an oropharyngeal cannula

\section{Phase 5 - Orotracheal intubation}

Perform videolaryngoscopy (Intubator).

Intubate with a 7.0-8.0 $\mathrm{mm}$ tracheal tube (in women) or 8.0-9.0 $\mathrm{mm}$ (in men) (Intubator).

Inflate the cuff while visualizing with the video laryngoscope (Assistant), verbally confirming the visualization (Intubator and Assistant).

Discard syringe in the waste bin (Assistant). 
Chart 1. (Continuation) Guide for RCDP in airway management of hypoxemic patients with suspected or confirmed COVID-19 infection.

\section{Phase 5 - Orotracheal intubation}

Hold the OTT close to the mouth (Assistant) while the Intubator pulls back the Bougie, holding it close to the connection with the Swivel.

Clamp OTT with strong clamps (Assistant).

Clamp OTT with strong forceps when the Bougie is above the Cuff outlet (Assistant).

Throw Bougie in the waste bin (Intubator).

Remove the swivel red cover and dispose of it in the waste bin (Assistant).

Connect the ventilation circuit (Intubator).

Unclamp the OTT (Assistant).

Ask the Assistant to hold / stabilize the OTT to avoid displacement (Intubator).

Remove external gloves and put on new gloves (Intubator).

Ask the attending physician or physical therapist to start mechanical ventilation (Intubator).

Confirm OTI through observation of chest expansion and $\mathrm{EtCO}_{2}$. Do not auscultate (Intubator).

Fix OTT (Intubator).

Place the videolaryngoscope blade in a plastic bag with double zip lock. Seal plastic bag (Assistant).

Remove external gloves and put on new gloves (Assistant).

If tracheal aspiration is necessary, use a closed system.

Administer Midazolam 5mg, Fentanyl 100 mcg, and Rocuronium 50 mg, (Intubator requests and Assistant administers it).

Ask the local medical team to maintain sedation and analgesia with appropriate drugs, verbally communicating what is administered (Intubator).

\section{Phase 6- Unattire}

Carry out unattire (see RCDP article for attire and unattire procedures ${ }^{13}$ ).

Abbreviations: PPE: Personal Protective Equipment; HEPA: High Efficiency Particulate Air; OTT: orotracheal tube; OTI: Orotracheal intubation.

\section{DISCUSSION}

In this study, instructions were given for conducting the training using rapid cycle deliberate practice for handling the airways of hypoxemic patients with suspected and positive COVID-19 infection. As seen above, the RCDP is an instructional simulation strategy centered on the learner that detects flaws in the individual's performance and allows them to be repaired through prescriptive feedbacks, which can improve individual or team deficiencies ${ }^{14}$.

Hence, situations are identified in which RCDP can be used to impact clinical performance. These situations are actual educational opportunities, which must include the following characteristics: existing and well-established performance guidelines; need for mastery of the skill; limited teaching time; low-volume, high-risk and urgent events; and team situations that require or benefit from specific choreographies ${ }^{14}$. The current pandemic situation has these characteristics, since the handling of the airways brings a high risk of contamination for professionals, has established guidelines and must be trained aiming at the mastery of the skill.

Several studies highlight the benefits of training with RCDP, the majority showing improvements in performance in cardiopulmonary resuscitation ${ }^{12,17,18}$, disclosing results of higher quality compressions, faster time to start compressions and defibrillation, including comparison with the standard American Heart Association training ${ }^{17,18}$. Other improvements observed are related to team communication and airway management ${ }^{17}$. From this perspective, a study on RCDP training for intubation choreography shows significantly higher residents' scores on the intubation checklist when compared to those who received post-scenario feedback. The study suggests that RCDP is an effective strategy to teach intubation skills, emphasizing the choreography of the procedure ${ }^{19}$.

Next, some technical aspects adopted for the creation of the guide for RCDP application will be briefly discussed, since the guide must be developed according to the reality of the institution regarding human and material resources.

A meticulous preparation for the procedure minimizes the chances of cross-infection and optimizes the chances of an effective and safe intubation. No flaws or imperfections are minimal when there is a risk for the patients and professionals involved. For this reason, the guide recommends the systematic double-checking of the human and material resources 
required to perform tracheal intubation, in addition to verbal confirmation of the performed actions, aiming at ensuring an effective and safe communication ${ }^{11,20}$. Moreover, it is recommended that the approach plan for airway handling, including alternative plans, be checked before the procedure and everyone must agree with it $^{8}$.

The use of the recommended personal protective equipment, although indispensable, frequently makes the performance of the procedure difficult, which can compromise the effectiveness of the process. The use of the N-95 mask, goggles, face shield, gown and other materials hinder communication and visualization, making it difficult to perform the intubation. A recent study indicated that 11 professionals reported their visualization was hindered by fogging in their masks $8,10,16$.

It is recommended that two professionals be present for intubation, and the most qualified professional must perform the procedure with the help of a second operator, aiming to optimize the success on the first attempt. A third participant can be on standby as an assistant and, if necessary, be asked to participate ${ }^{8,16}$

The recommended intubation technique is the fastsequence technique in an attempt to avoid the use of bagvalve-mask ventilation and to optimize sedation/analgesia/ neuromuscular block. A bag-valve-mask ventilation before the intubation is considered a high-risk procedure for the generation of aerosols, and inadequate sedation can put the intubator at risk if the patient coughs and becomes agitated, also including the risk of dislodging the PPE ${ }^{10,11,20-23}$.

The use of a videolaryngoscope is recommended instead of the traditional laryngoscopy, aiming to optimize the success of the procedure on the first attempt ${ }^{10,11,20}$. In this guide, the intubation strategy is presented with the use of an introducer (Bougie) through the swivel as it would work as an effective seal against aerosols.

Pre-oxygenation for three to five minutes is recommended to optimize the conditions for the procedure, if possible with headboard elevation; however, there is lack of evidence in the literature regarding the ideal device for performing the pre-oxygenation ${ }^{8,10,11,20}$. It has been proposed in this training guide to use the CPAP valve coupled to a Mapleson $C$ system, which seems to be effective in the pre-oxygenation of patients, even those initially very hypoxemic and obese.

\section{CONCLUSION}

In this article, theoretical, conceptual aspects and detailed operational instructions for applying the Rapid Cycle Deliberate Practice are presented aiming to instrumentalize health services in conducting training. This instructional strategy seems to be beneficial to train professionals to attain skill mastery to perform the orotracheal intubation procedure when dealing with severe forms of coronavirus disease (Covid-19), aiming to minimize the risk of contamination. This initiative is in agreement with the incentive of the authors who created the RCDP strategy to apply it in contexts other than the original one, of cardiopulmonary resuscitation, aiming to test its applicability in other situations and institutions. In addition, it provides for the incorporation of in-service training, with an emphasis on the evidence-based theory-practice binomial.

The article was limited to the stage of creating the RCDP application guide, in addition to providing theoretical and operational subsidies for its applicability. However, it is recommended that the guide be validated by specialists and it is suggested that clinical studies be carried out to generate concrete results on the applicability of the RCDP in this scenario. It should be noted that adjustments can be made to this guide both to meet the reality of the institutions and due to updates of evidence / recommendations.

\section{AUTHORS' CONTRIBUTION}

Rodrigo Pereira Diaz André: Study conception and design; Writing of the manuscript, being responsible for writing the aspects concerning orotracheal intubation. Hudson Carmo de Oliveira: Study conception and design; Writing of the manuscript, being responsible for writing the aspects related to the Rapid Cycle Deliberate Practice. Glauber Gouvêa: Analysis and interpretation of data; Critical review of important intellectual content, being responsible for reviewing the orotracheal intubation content. Fátima Carneiro Fernandes: Analysis and interpretation of data; Critical review of important intellectual content, being responsible for the review of the entire article. Ingrid Régia Lopes Jerônimo: Analysis and interpretation of data; Critical review of important intellectual content, being responsible for reviewing the content on Rapid Cycle Deliberate Practice. Juliana Faria Campos: Study conception and design; Writing of the manuscript, being responsible for the problematization and layout of the article in general; Critical review of the important intellectual content, acting as advisor and general reviewer of the article.

\section{CONFLICTS OF INTEREST}

The authors declare no conflicts of interest.

\section{SOURCES OF FUNDING}

Coordenação de Aperfeiçoamento de pessoal de Nível Superior (CAPES) - Ministry of Education. Author Hudson Carmo de Oliveira. Academic Excellence Program. Process number: 88887.471399/2019-00. 


\section{REFERENCES}

1. World Health Organization. Coronavirus disease 2019 (Covid-19) Situation report no 117 [access in 17 may 2020]. Available from: https://www.who. int/docs/default-source/coronaviruse/situation-reports/20200516-covid19-sitrep-117.pdf?sfvrsn=8f562cc_2.

2. Guan WJ, Ni ZY, Hu Y, Liang WH, Ou CQ, He JX, et al. Clinical characteristics of coronavirus disease 2019 in China. N Engl J Med. 2020;382:1708-20. doi: 10.1056/NEJMoa2002032.

3. Wang D, Hu B, Hu C, Zhu F, Liu X, Zhang J, et al. Clinical characteristics of 138 hospitalized patients with 2019 novel coronavirus-infected pneumonia in Wuhan, China. JAMA. 2020;323(11):1061-9. doi: 10.1001/jama.2020.1585.

4. Yang X, Yu Y, Xu J, Shu H, Xia J, Liu H, et al. Clinical course and outcomes of critically ill patients with Sars-CoV-2 pneumonia in Wuhan, China: a single-centered, retrospective, observational study. Lancet Respir Med. 2020;8(5):475-81. doi:10.1016/S2213-2600(20)30079-5.

5. Tran K, Cimon K, Severn M, Pessoa-Silva CL, Conly J. Aerosol generating procedures and risk of transmission of acute respiratory infections to healthcare workers: a systematic review. PLoS One. 2012;7(4):e35797.

6. Chinese Society of Anesthesiology, Chinese Association of Anesthesiologists. Perioperative management of patients infected with the novel coronavirus. Anesthesiology. 2020;132:1307-16.

7. World Health Organization. Summary of probable Sars cases with onset of illness from 1 November 2002 to 31 July 2003 [access in 7 feb 2020]. Available from: https://www.who.int/csr/sars/country/table2004_04_21/en.

8. Yao W, Wang T, Jiang B, Gao F, Wang L, Zheng H, et al. Emergency tracheal intubation in 202 patients with Covid-19 in Wuhan, China: lessons learnt and international expert recommendations. $\mathrm{Br} J$ Anaesth. 2020;125(1):e28ee37.

9. Gonzalez L, Kardong-Edgren S. Deliberate practice for mastery learning in nursing. Clin Simul Nurs. 2016;13(1):10-4. doi: 10.1016/j.ecns.2016.10.005.

10. Chen X, Liu Y, Gong Y, Guo X, Zuo M, Li J, et al. Perioperative Management of patients infected with the novel coronavirus recommendation from the joint task force of the Chinese Society of Anesthesiology and the Chinese Association of Anesthesiologists. Anesthesiology 2020;132(6):1307-16. doi: 10.1097/ALN.0000000000003301.

11. Anaesthesia and caring for patients during the Covid-19 outbreak. Australian Society of Anaesthetists. For the latest version, please visit https://asa.org.au/covid-19-updates/.

12. Hunt EA, Duval-Arnould JM, Nelson-McMillan KL, Bradshaw JH, Diener-West $M$, Perretta JS, et al. Pediatric resident resuscitation skills improve after "Rapid Cycle Deliberate Practice" training. Resuscitation. 2014;85(7):945-51.
13. Oliveira HC, Souza LC, Leite TC, Campos JF. Personal protective equipment in the coronavirus pandemic: training with Rapid Cycle Deliberate Practice. Rev Bras Enferm. 2020;73(Suppl 2):e20200303. doi: 10.1590/0034-71672020-0303.

14. Perretta JS, Duval-Arnould J, Poling S, Sullivan N, Jeffers JM, Hunt EA, et al. Best practices and theoretical foundations for simulation instruction using Rapid-Cycle Deliberate Practice. Simul Healthc. 2020;15(5):356-62. doi: $10.1097 /$ SIH.0000000000000433.

15. Ericsson KA. Deliberate practice and acquisition of expert performance: a general overview. Acad Emerg Med. 2008;15(11):988-94.

16. Agência Nacional de Vigilância Sanitária. Nota Técnica nº 04/2020. Orientações para serviços de saúde: medidas de prevenção e controle que devem ser adotadas durante a assistência aos casos suspeitos ou confirmados de infecção pelo novo coronavírus (Sars-CoV-2). Brasília: Anvisa; 2020.

17. Hunt E, Duval-Arnould J, Chime N, Jones K, Rosen M, Hollingsworth $M$, et al. Integration of in-hospital cardiac arrest contextual curriculum into a basic life support course: a randomized, controlled simulation study. Resuscitation. 2017;114(5):127-32.

18. Sullivan N, Duval-Arnould J, Twilley M, Smith SP, Aksamit D, Boone-Guercio $P$, et al. Simulation exercise to improve retention of cardiopulmonary resuscitation priorities for in-hospital cardiac arrests: a randomized controlled trial. Resuscitation. 2015;86(1):6-13.

19. Gross I, Abrahan D, Kumar A, Noether J, Shilkofski NA, Pell P, et al. Rapid Cycle Deliberate Practice (RCDP) as a method to improve airway management skills: a randomized controlled simulation study. Cureus 2019;11(9):e5546.

20. Wax RS, Christian MD. Practical recommendations for critical care and anesthesiology teams caring for novel coronavirus (2019-nCoV) patients. Can J Anesth. 2020;67:568-76. doi: 10.1007/s12630-020-01591-x.

21. World Health Organization. Novel coronavirus (2019-nCoV) technical guidance: infection prevention and control. WHO, 2020. [access in 9 feb 2020]. Available from: https://www.who.int/emergencies/diseases/novelcoronavirus-2019/technical-guidance/infection- prevention-and-control.

22. Centers for Disease Control and Prevention. Interim infection prevention and control recommendations for patients with confirmed 2019 novel coronavirus (2019-nCoV) or persons un- der investigation for 2019$\mathrm{nCoV}$ in healthcare settings. Centers for Disease Control and Prevention, 2020. [access in 9 feb 2020]. Available from: https://www.cdc.gov/ coronavirus/2019-nCoV/ hcp/infection-control.html.

23. University of Toronto. Coronavirus and safety precaution. University of Toronto, 2020. [access in 9 feb 2020]. Available from: https://www. anesthesia.utoronto.ca/news/coronavirus-and-safety-precautions. 